\title{
Adaptive perturb and observe maximum power point tracking with current predictive and decoupled power control for grid- connected photovoltaic inverters
}

\author{
Yong YANG ${ }^{1}$, Huiqing $\mathrm{WEN}^{2}$
}

\begin{abstract}
In order to improve maximum power point tracking (MPPT) performance, a variable and adaptive perturb and observe $(\mathrm{P} \& \mathrm{O})$ method with current predictive control is proposed. This is applied in three-phase threelevel neutral-point clamped (NPC) photovoltaic (PV) generation systems. To control the active power and the reactive power independently, the decoupled power control combined with a space vector modulation block is adopted for three-phase NPC inverters in PV generation systems. To balance the neutral-point voltage of the three-phase NPC grid-connected inverter, a proportional and integral control by adjusting the dwell time of small voltage vectors is used. A three-phase NPC inverter rated at $12 \mathrm{kVA}$ was established. The performance of the proposed method was tested and compared with the fixed perturbation MPPT algorithm under different conditions. Experimental results confirm the feasibility and advantages of the proposed method.
\end{abstract}

Keywords Maximum power point tracking (MPPT), Perturb and observe (P\&O), Current predictive control,

CrossCheck date: 13 June 2018

Received: 30 November 2017/Accepted: 13 June 2018/Published online: 23 August 2018

(C) The Author(s) 2018

Yong YANG

yangy1981@suda.edu.cn

Huiqing WEN

Huiqing.Wen@xjtlu.edu.cn

1 School of Rail Transportation, Soochow University, Suzhou 215137, China

2 Department of Electrical and Electronic Engineering, Xi'an Jiaotong-Liverpool University, Suzhou 215123, China
Decoupled power control, Three-phase neutral-point clamped inverter

\section{Introduction}

With increasing energy consumption, the importance of developing renewable energy sources is highlighted. Among different renewable energy sources, the photovoltaic (PV) energy source is considered one of the most promising clean energy sources because of its wide distribution and ease of utilization [1-5].

The curve for power versus voltage or power versus current of the PV array is nonlinear, and the output power of the PV array is dependent on irradiation as well atmospheric temperature. In order to realize the maximum utilization of the PV array, maximum power point tracking (MPPT) becomes of great significance in PV generation systems [6-8]. Recently, many MPPT algorithms have been presented, varying in structural complexity, control accuracy, response time, and cost. It is well known that the perturbation and observe (P\&O) MPPT algorithm is the most popular because of its simple structure and control [6-8]. However, the conventional P\&O method often suffers from some demerits. For instance, a large perturbation value will result in high PV array oscillations, while the dynamic response speed will be affected using a small perturbation value. Hence, a trade-off between steady-state oscillation and fast response is generated for the conventional fixed perturbation $\mathrm{P} \& \mathrm{O}$ method. Another wellknown MPPT scheme is incremental conductance (INC), which achieves maximum power point (MPP) by comparing the INC of the PV array [9-11]. However, the INC method hardly achieves the real MPP in practical situations because of hardware limitations. To improve MPPT 
performance, an adaptive P\&O MPPT technique based on a proportional and integral (PI) controller has been proposed [12]. This can achieve good steady-state and dynamic performance. However, this MPPT performance will heavily rely on the PI parameters, and the adjustment of PI parameters is difficult. Recently, intelligent control algorithms have been used to realize MPPT algoriths in distributed generation systems [13-15]. In [13], a fuzzy logic controller for MPPT was proposed. This achieves good steady and dynamic MPPT performance. However, the effectiveness of the fuzzy logic controller largely relies on the skill and experience of the designer. Similarly, an artificial neural network (ANN) intelligent algorithm was presented in $[14,15]$. This exhibits perfect performance in MPPT, but it consumes a large computation time when implementing the MPPT algorithms with a digital signal processor (DSP).

In recent years, the implementation of digitally controlled techniques has been widely used in distributed generation systems, such as current predictive control, model predictive control (MPC), and model predictive power control [16-24]. Among different predictive methods, MPC has become very popular. MPC makes full play of limited switching states for power converters, and a cost function is employed to evaluate each switching state, and the switching state with minimum cost function will be selected and applied in the next control cycle. MPC can be applied in DC-DC converters and a fast response under irradiance change for MPPT has been achieved [18-20]. However, the MPC algorithm uses only one voltage vector in every switching period, and it needs high switching frequency to ensure performance improvement. Another method is current predictive control, which is essentially a digital control strategy and has been broadly employed in power electrics converters and motor drives [21-24]. In practical implementation, the duty ratio in the next switching cycle is directly calculated by the measured signals, the input and the output information. Compared with traditional PI control, current predictive control can realize better dynamic performance.

Inverters, considered as the bridge between generation systems and power grid or loads, are widely used. Compared with two-level inverters, three-level inverters have many advantages such as less total harmonic distortion (THD) of inverter output voltages, lower output filter size, and higher efficiency [25-28]. For three-phase three-level neutral-point clamped (NPC) inverters, the most popular control strategy is voltage-oriented control (VOC), which achieves decouple control for the active and reactive powers. However, its performance is largely dependent on the inner current-loop control [29, 30]. Another wellknown control strategy is called direct power control, in which the active power and the reactive power are directly regulated by the appropriate selection of a voltage vector from a switching table. Direct power control strategy has advantages of simple control and quick response, but the switching frequency is not fixed, which will result in difficult filter design [31, 32]. For three-phase three-level NPC inverters, one common question is how to balance the neutral-point (NP) voltage. To regulate the NP voltage to half of the DC-link voltage, different balancing control strategies have been proposed. These can be divided into hardware methods and software methods [33-36]. Hardware methods need extra hardware circuits to balance NP voltage, and this will increase the cost and size of the system. Software methods can mainly be classified into carrier-based pulse width modulation (CB-PWM) and space vector PWM (SV-PWM). Compared with the CBPWM method, the SV-PWM method has many benefits, such as small NP voltage ripple and high DC voltage utilization [35, 36].

In this paper, a variable and adaptive $\mathrm{P} \& \mathrm{O}$ method with current predictive control is proposed. This is applied in three-phase three-level NPC grid-connected photovoltaic generation systems. The decoupled power control (DPC) combined with a space vector modulation (SVM) block is used and the NP voltage is well balanced by selecting proper small voltage vectors. A $12 \mathrm{kVA}$ three-phase NPC inverter prototype was built and a 32-bit DSP (TMS320F2808) was adopted to realize the control strategy. Main experimental results were obtained for both the steady-state and dynamic responses to show the effectiveness of the proposed method.

\section{PV generation systems and control strategy}

\subsection{PV generation configuration}

A three-phase three-level NPC grid-connected photovoltaic generation system is depicted in Fig. 1. The PV generation system contains a PV array, a boost converter, three-phase three-level NPC inverters, an LC filter, and a power grid. In the PV generation systems, the PV array converts sunlight into electricity; the boost inverter is the power interface and achieves MPPT, and the three-phase three-level NPC inverter is employed to control the active power and the reactive power. In Fig. 1, $V_{P V}$ and $I_{P V}$ stand for input voltage and current of PV array; $e_{\mathrm{a}}, e_{\mathrm{b}}, e_{\mathrm{c}}$ are the grid voltages of phases $\mathrm{a}, \mathrm{b}$, and $\mathrm{c}$, respectively; $i_{\mathrm{a}}, i_{\mathrm{b}}, i_{\mathrm{c}}$ are the inverter grid currents of phases a, b, and c, respectively; $V_{p}$ and $V_{n}$ represent the upper and lower DC-link voltages; $U_{\mathrm{DC}}$ is the total DC-link voltage; $i_{N}$ is the NP current. 


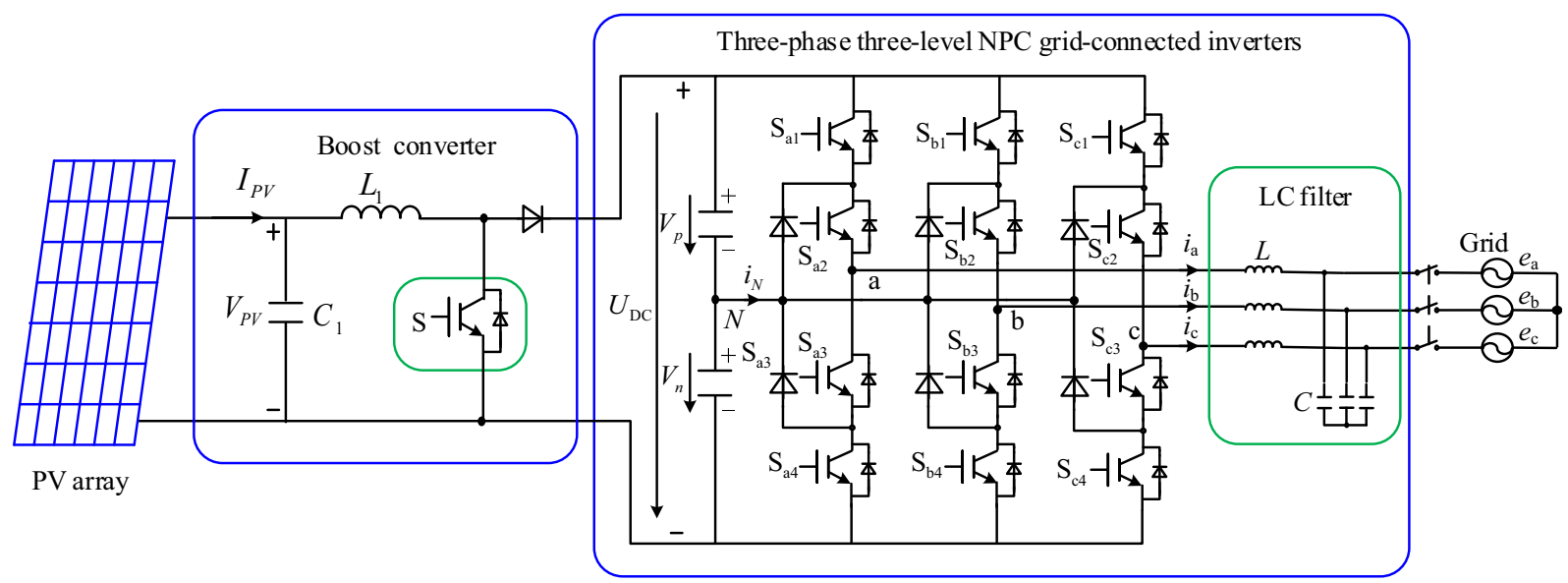

Fig. 1 Three-phase three-level NPC grid-connected PV generation system

\subsection{Implementation of current predictive control}

The current predictive control method is to obtain the coming current value on the basis of the current predictive model, which is extensively used in power electronic converters. As shown in Fig. 1, when the boost converter switch $\mathrm{S}$ is turned on, the PV array current can be expressed as follows.

$L_{1} \frac{\mathrm{d} I_{P V}}{\mathrm{~d} t}=V_{P V}$

When the boost converter switch S is turned off, the boost converter voltage equation can be obtained as:

$L_{1} \frac{\mathrm{d} I_{P V}}{\mathrm{~d} t}=V_{P V}-U_{\mathrm{DC}}$

Applying a sampling period $T_{s}$, the derivative form $\mathrm{d} I_{P V} / \mathrm{d} t$ can be approximated by:

$L_{1} \frac{\mathrm{d} I_{P V}}{\mathrm{~d} t} \approx L_{1} \frac{I_{P V}(k+1)-I_{P V}(k)}{T_{s}}$

Substituting (1) and (2) into (3), the relationships between the discrete-time variables can be derived as:

$I_{P V}(k+1)=I_{P V}(k)+\frac{T_{s}}{L_{1}} V_{P V}(k)$

$I_{P V}(k+1)=I_{P V}(k)+\frac{T_{s}}{L_{1}}\left(V_{P V}(k)-U_{\mathrm{DC}}(k)\right)$

The goal of current predictive control is to make the boost converter inductor current track the current reference. The boost converter inductance current waveform is displayed in Fig. 2. At the $k$ th sampling instant in a sampling period $T_{s}$, the on-time of power switch $\mathrm{S}$ is assumed to be $d(k) T_{s}$, and the off-time of power switch $\mathrm{S}$ is considered to be $(1-d(k)) T_{s}$. Since the input PV array voltage $V_{P V}$ and the output voltage DC-link voltage $U_{\mathrm{DC}}$ are slowly changing compared with the sampling period,

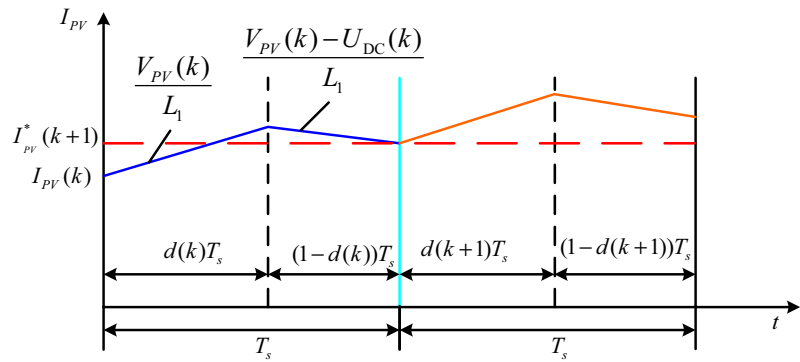

Fig. 2 Typical boost converter inductor current waveform using current predictive control

they can be considered as constant during a switching period. The boost converter inductor current $I_{P V}(k+1)$ at the $(k+1)$ th sampling period can be predicted using the input PV array voltage $V_{P V}$, the output voltage DC-link voltage $U_{\mathrm{DC}}$, the boost converter inductance $L_{1}$, the switching duty ratio $d(k)$, and the switching period $T_{s}$. From (4), (5), and Fig. 2, the predictive current $I_{P V}(k+1)$ can be obtained as follows:

$$
\begin{aligned}
I_{P V}(k+1)= & I_{P V}(k)+\frac{d(k) T_{s}}{L_{1}} V_{P V}(k) \\
& +\frac{(1-d(k)) T_{s}}{L_{1}}\left(V_{P V}(k)-U_{\mathrm{DC}}(k)\right)
\end{aligned}
$$

Solving (6), the predicted duty cycle can be obtained as:

$$
d(k)=1-\frac{1}{U_{\mathrm{DC}}(k)}\left[\frac{L_{1}}{T_{s}}\left(I_{P V}(k)-I_{P V}(k+1)\right)+V_{P V}(k)\right]
$$

The predictive boost converter current $I_{P V}(k+1)$ should follow the reference current $I_{P V}^{*}(k+1)$ at the next sampling period $T_{s}$. Therefore, the predicted duty cycle can be derived from (7) as: 
$d(k)=1-\frac{1}{U_{\mathrm{DC}}(k)}\left[\frac{L_{1}}{T_{s}}\left(I_{P V}(k)-I_{P V}^{*}(k+1)\right)+V_{P V}(k)\right]$

The PV array current reference $I_{P V}^{*}(k+1)$ at the $(k+1)$ th sampling instant can be derived by applying a second-order linear interpolation method, which can be given as:

$I_{P V}^{*}(k+1)=3\left(I_{P V}^{*}(k)-I_{P V}^{*}(k-1)\right)+I_{P V}^{*}(k-2)$

where $I_{P V}^{*}(k-1)$ is the PV array current reference at one previous sampling time; $I_{P V}^{*}(k-2)$ is the PV array current reference at two previous sampling times.

\subsection{MPPT control}

As is well known, the power-voltage $(P-V)$ or currentvoltage $(I-V)$ characteristic of a PV array is nonlinear and shows one single MPP under normal operational conditions. For the conventional $\mathrm{P} \& \mathrm{O}$ algorithm, if the power change against the voltage change $\mathrm{d} P_{P V} / \mathrm{d} V_{P V}$ of the PV string satisfies $\mathrm{d} P_{P V} / \mathrm{d} V_{P V}>0$, the $\mathrm{P} \& \mathrm{O}$ scheme will make the PV array reference voltage operate in the same perturbation direction. If the perturbation voltage value in the previous time is positive or negative, the PV array reference voltage $V_{P V}^{*}$ will increase or decrease. On the other hand, when the power change against the voltage change $\mathrm{d} P_{P V} / \mathrm{d} V_{P V}$ of the PV array meets $\mathrm{d} P_{P V} / \mathrm{d} V_{P V}<0$, the P\&O method will make the $\mathrm{PV}$ array reference voltage work in the reverse perturbation direction. In this paper, a variable and adaptive $\mathrm{P} \& \mathrm{O}$ method with current predictive control is proposed, and the operation principle of the system is as follows:

1) The PV string voltage $V_{P V}(k)$ and string current $I_{P V}(k)$ at the $k$ th sampling period are measured by the PV array voltage sensor and PV array current sensor.

2) The PV array power variation slowly changes and remains constant over the period of a sampling time. Therefore, a delay of 400 samples $(20 \mathrm{~ms})$ is used to produce two successive samples for the PV array power. This will reduce the computation burden for the MPPT algorithm [10]. The PV string power is calculated at the present sampling instant and the 400 previous sampling instants using the measured PV array voltage and current as follows:

$$
\begin{aligned}
& P(k)=V_{P V}(k) I_{P V}(k) \\
& P(k-400)=V_{P V}(k-400) I_{P V}(k-400)
\end{aligned}
$$

3) The power variation $\Delta P(k)$ of the PV string within the 400 sampling times $\left(400 T_{s}\right)$ can be obtained as:

$$
\Delta P(k)=P(k)-P(k-400)
$$

4) Calculate the PV array voltage reference using an adaptive and variable step method as:

$$
\begin{array}{r}
V_{r e f}(n)=V_{r e f}(n-1)+M\left|\frac{P(k)-P(k-400)}{V_{P V}(k)-V_{P V}(k-400)}\right| \\
=V_{\text {ref }}(n-1)+\Delta V_{\text {ref }}
\end{array}
$$

where $V_{\text {ref }}(n)$ is the present $\mathrm{PV}$ array voltage reference; $V_{\text {ref }}(n-1)$ is the previous $\mathrm{PV}$ array voltage reference; $M$ is the step size. The perturbation voltage $\Delta V_{\text {ref }}$ can be given as:

$$
\Delta V_{\text {ref }}=M\left|\frac{P(k)-P(k-400)}{V_{P V}(k)-V_{P V}(k-400)}\right|
$$

From (14), it can be seen that the power change against the voltage change represents the irradiation change in terms of the $P-V$ curve of a PV array. If the irradiation change is small, the value of the power change against the voltage change is small. In the contrary case, the value will be large. When $\Delta V_{\text {ref }}$ is changing over a large range as a result of environmental variation, this algorithm will change $\Delta V_{\text {ref }}$ to a large value in order to realize fasttracking MPP. Once $\Delta V_{\text {ref }}$ is small, the MPPT algorithm assumes that the control system has reached the steadystate stage and $\Delta V_{\text {ref }}$ will be tuned to be small in order to make the power fluctuation small. Therefore, the disturbance step $\Delta V_{r e f}$ of the MPPT algorithm is not fixed but adaptive according to environmental variation. This will improve MPPT efficiency. The flowchart of the variable and adaptive MPPT control is depicted in Fig. 3.

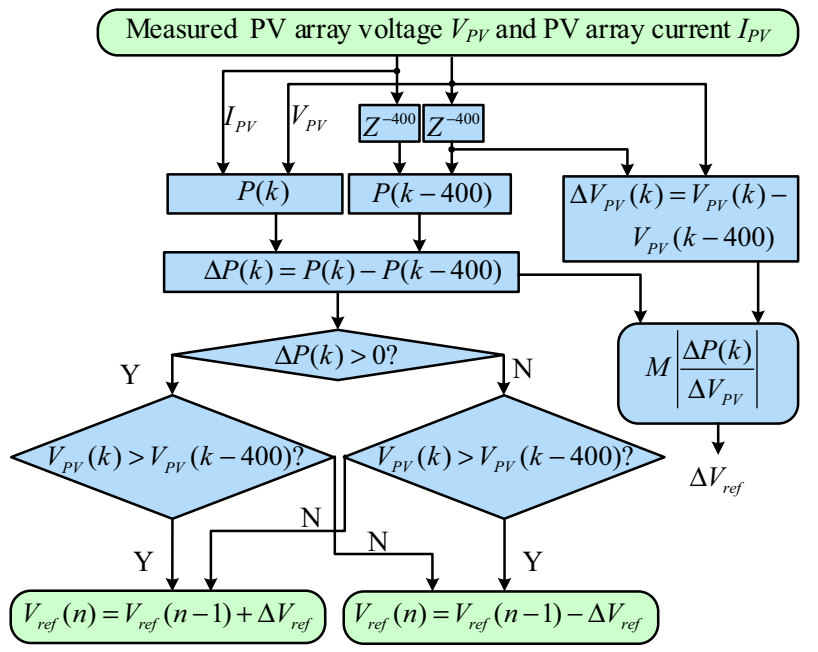

Fig. 3 Flowchart of variable and adaptive MPPT control 
Because of its simple structure and high efficiency, the boost DC-DC converter is adopted to realize the MPPT algorithm in the system. For the proposed current predictive control, the control scheme of the adaptive and variable-step MPPT is illustrated in Fig. 4. Compared with conventional control, the proposed MPPT algorithm uses the current predictive control as the inner loop. The PI controller is employed as the outer loop for both methods. In the outer loop, the given voltage $V_{P V}^{*}$ of the PV array is realized by the variable and adaptive MPPT control, and the difference between the given PV array voltage $V_{P V}^{*}$ and the measured voltage $V_{P V}$ is sent to the conventional PI controller. In the inner loop, the current reference $I_{P V}^{*}$ of the PV string is set from the outer voltage PI controller, and the predicted duty cycle can be derived by the current predictive controller or the PI controller. A simple modulation generates the switching pulse of the boost converter.

\subsection{NP voltage balancing for three-phase NPC inverters}

For three-phase three-level inverters, the operational status of each leg has three switching states, which can be represented by $[\mathrm{P}],[\mathrm{O}]$, and $[\mathrm{N}]$. Switching states of the inverter can use two pairs of complementary controlled power switches $\left(\mathrm{S}_{x 1}, \mathrm{~S}_{x 2}\right)$ and $\left(\mathrm{S}_{x 2}, \mathrm{~S}_{x 4}\right)$ for every phase $x$, where $x$ can be a, b, and c. Switching state $[\mathrm{P}]$ means that the upper power switches $\left(S_{x 1}, S_{x 2}\right)$ in Fig. 1 are turned on at the same time. Switching state $[\mathrm{O}]$ indicates that the middle power switches $\left(\mathrm{S}_{x 2}, \mathrm{~S}_{x 3}\right)$ are turned on at the same time, and switching state $[\mathrm{N}]$ demonstrates that the down switches $\left(\mathrm{S}_{x 3}, \mathrm{~S}_{x 4}\right)$ are on in the meantime. As shown in Fig. 1, switching state $[\mathrm{P}]$, switching state $[\mathrm{O}]$, and switching state $[\mathrm{N}]$ mean the inverter output voltage is $+U_{\mathrm{DC}} / 2,0$ and

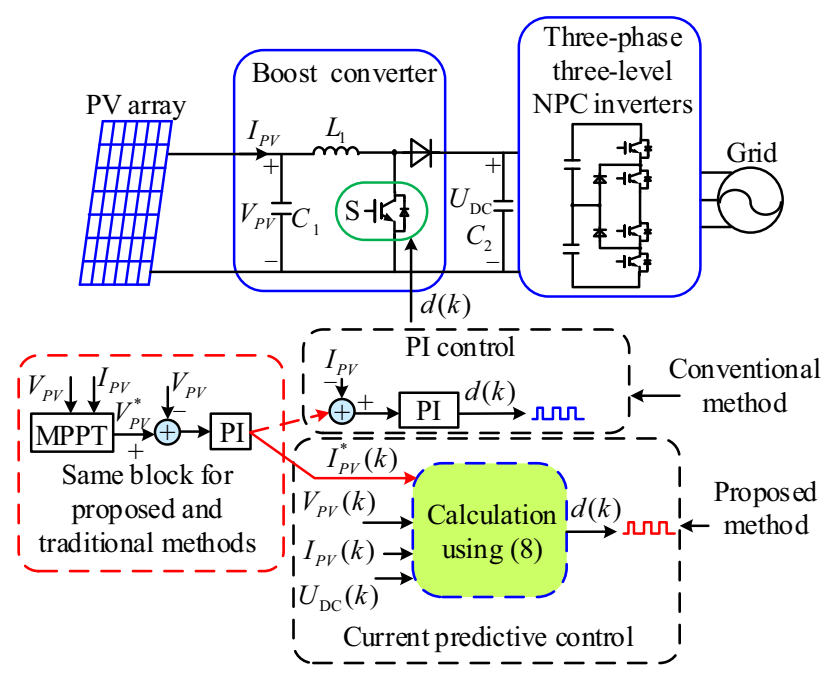

Fig. 4 Control scheme of proposed adaptive and variable-step MPPT algorithm
$-U_{\mathrm{DC}} / 2$, respectively, when the NP defines the reference voltage. The three-phase three-level NPC inverter can generate 27 space voltage vectors. In terms of the magnitude of space voltage vectors, it can be divided into zero voltage vectors, small voltage vectors, medium voltage vectors, and large voltage vectors $[33,34]$. For large voltage vectors, the NPC inverter outputs connect only to the positive DC rail or the negative DC rail, not to the NP. Therefore, large voltage vectors do not affect the NP voltage. For zero vector voltages, the inverter outputs simultaneously connect to the positive DC rail, the negative $\mathrm{DC}$ rail, or the NP, and also do not influence the NP voltage. For medium vector voltages, there is an inverter output connected to the NP, which will influence the NP voltage and will discharge or charge the DC-link capacitors in terms of inverter output currents. For small vector voltages, at least one of the inverter outputs is connected to the NP. For the influence on the NP voltage, small vector voltages can be further classified as positive small vector voltages and negative small vector voltages. These output the same voltage but with opposite influence on the NP voltage. The voltage difference between the upper DC-link voltage and the lower DC-link voltage is defined as $\Delta u_{d}=V_{p}-V_{n}$. When the phase of the grid current $i_{\mathrm{a}}$ satisfies $i_{\mathrm{a}}>0$ in Fig. 1, the positive voltage vector [POO] will decrease the upper DC-link voltage $V_{p}$ and the voltage difference $\Delta u_{d}$, and the negative voltage vector [ONN[ will increase $V_{p}$ and $\Delta u_{d}$. If the grid phase a current is $i_{\mathrm{a}}<0$, the upper DC-link voltage $V_{p}$ and the voltage difference $\Delta u_{d}$ will operate in the opposite direction $[35,36]$. From the above analysis, it can be concluded that small vector voltages come in pairs and each pair has an opposite influence on the NP voltage. Therefore, balancing the NP voltage is realized by choosing the appropriate small vector voltages. Assuming the total dwell time of a pair of small vector voltages is $T_{\text {total }}$, the dwell time of a positive small vector voltage is defined as:

$T_{p}=m T_{\text {total }} \quad 0 \leq m \leq 1$

From (15), the dwell time of the negative small vector voltage can be obtained as:

$T_{n}=(1-m) T_{\text {total }} \quad 0 \leq m \leq 1$

The control strategy for balancing the NP voltage is depicted in Fig. 5. The voltage difference $\Delta u_{d}$ is sent to the PI controller, and the output of the PI controller regulates the value $m$ according to the direction of the NP current $i_{N}$. The NP current $i_{N}$ can be acquired by relationships between the inverter output currents and the switching states of the NPC inverters, and the NP current $i_{N}$ will not be measured $[35,36]$. If the voltage difference $\Delta u_{d}$ is large, the PI output value $m$ will also become large and the dwell time of the small vector voltage will be large. The result will be just the opposite when the value $m$ is small. Therefore, the NP voltage is automatically adjusted. 


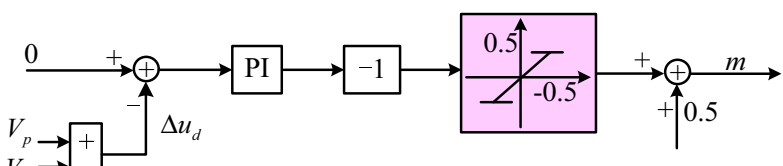

(a) NP current $i_{N}<0$

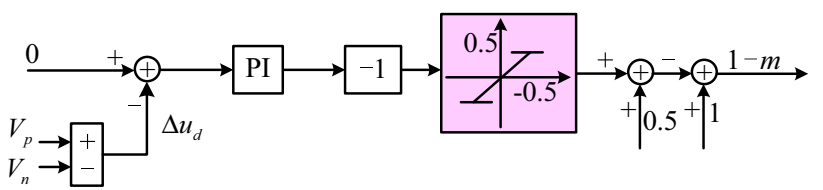

(b) NP current $i_{N}>0$

Fig. 5 Control scheme for balancing NP voltage

\subsection{Decoupled power control for NPC inverters}

According to instantaneous power theory and coordinate transformation, the active power $P$ and the reactive power $Q$ for three-phase three-level inverters in the $d q$ rotating reference frame can be obtained as [29]:

$\left\{\begin{array}{l}P=e_{d} i_{d}+e_{q} i_{q} \\ Q=e_{q} i_{d}-e_{d} i_{q}\end{array}\right.$

where $e_{d}$ and $e_{q}$ are the $d$-axis and $q$-axis grid voltage in the $d q$ rotating reference frame; $i_{d}$ and $i_{q}$ are the $d$-axis and $q$ axis grid currents in the $d q$ rotating reference frame.

Combined with SVM, the DPC strategy for the threephase three-level NPC grid-connected inverter is described in Fig. 6. The special phase locked loop (PLL), called a 'positive sequence detector (PSD) $+d q-\mathrm{PLL}$ ', which is free of grid voltage harmonics, is widely used in distributed generation systems [37]. Therefore, it is employed in this paper. To reduce the harmonic currents of the NPC inverter currents caused by low-order harmonics in grid voltages, the grid voltage feed-forward control is used [37]. The NPC inverter has to realize two goals. The first goal is to stabilize the DC-link voltage, and the second is to transform active and reactive powers to the power grid under different irradiation in photovoltaic generation systems. From Fig. 6, it can be seen that the control scheme contains two loops. The outer loop is a DC-link voltage loop for stabilizing the DC-link voltage, and the inner loop is a power loop for tracking the given powers. The measured DC-link voltage $U_{\mathrm{DC}}$ subtracts the reference DC-link voltage $U_{\mathrm{DC}}^{*}$, and the error is sent to a conventional PI controller. The active power reference $P^{*}$ can be acquired after the output signal of the DC-link PI controller multiplying the measured DC-link voltage $U_{\mathrm{DC}}$. The reactive power reference $Q^{*}$ can be set in terms of the requirements of power systems, which can be set to absorb reactive power from the power grid or to send reactive power to the power grid. The active and reactive power errors between the power references and the calculated powers are sent to power PI controllers. The $d$-axis voltage reference $u_{d}^{*}$ can be obtained after an output signal from the active power PI controller adding the $d$-axis grid voltage $e_{d}$. In the same way, the $q$-axis voltage reference $u_{q}^{*}$ is calculated as the output of the reactive power PI controller plus $q$-axis grid voltage $e_{q}$. With the help of the PSD $+d q$-PLL method, the $d$-axis voltage references $u_{d}^{*}$ and the $q$-axis voltage references $u_{q}^{*}$ can be transformed into the $\alpha$-axis voltage references $u_{\alpha}^{*}$ and the $\beta$-axis voltage references $u_{\beta}^{*}$ through coordinate transformation. The output 12-pulse signals for the three-phase NPC inverter, which determine the current states of the power switches, can be acquired by the SVM algorithm using the $\alpha$-axis voltage references $u_{\alpha}^{*}$, the $\beta$-axis voltage references $u_{\beta}^{*}$, and the output of balancing the NP voltage PI controller.

\section{Experimental results}

\subsection{Experimental test bench and parameters}

To further validate the feasibility and correctness of the proposed control strategy, an experimental block diagram based on the TI 32-bit DSP (TMS320F2808) is used and shown in Fig. 7. The inverter output currents and PV array current are acquired by a VAC current sensor 4646-X400, and the upper DC-link voltage, the lower DC-link voltage, PV array voltage, and grid phase voltages are sampled by an LEM voltage sensor LV25-P. The current and voltage signals are sent to a 12-bit DSP internal analog to a digital (A/D) port. A complex programmable logic control device (CPLD) expands the PWM pulse signals generated by the TMS320F2808 chip. A power module is used as a leg for the three-phase three-level inverter. The experimental parameters are listed in Table 1. To simulate PV array characteristics, a programmable DC source Topcon Quadro $32 \mathrm{~K}$ is used. This can change the PV array curve through a monitored interface.

In the experiment, three PV string curves are used. For the first PV string, the main PV array parameters are set as open-circuit voltage $V_{o c 1}=650 \mathrm{~V}$, short-circuit current $I_{s c 1}=13.5 \mathrm{~A}$, and MPPT voltage $V_{M P P T 1}=520 \mathrm{~V}$. The second curve is set with main parameters of $V_{o c 2}=650 \mathrm{~V}$, $I_{s c 2}=27 \mathrm{~A}$, and $V_{M P P T 2}=520 \mathrm{~V}$, and the third curve is set at $V_{o c 3}=750 \mathrm{~V}, I_{s c 3}=8 \mathrm{~A}$, and $V_{M P P T 3}=600 \mathrm{~V}$.

\subsection{MPPT}

\section{1) Steady-state performance of MPPT}

In the steady-state test, the DC-link voltage reference $U_{\mathrm{DC}}^{*}$ is given as $620 \mathrm{~V}$, and the reactive power reference $Q^{*}$ is set to zero in order to achieve a unity power factor. The 


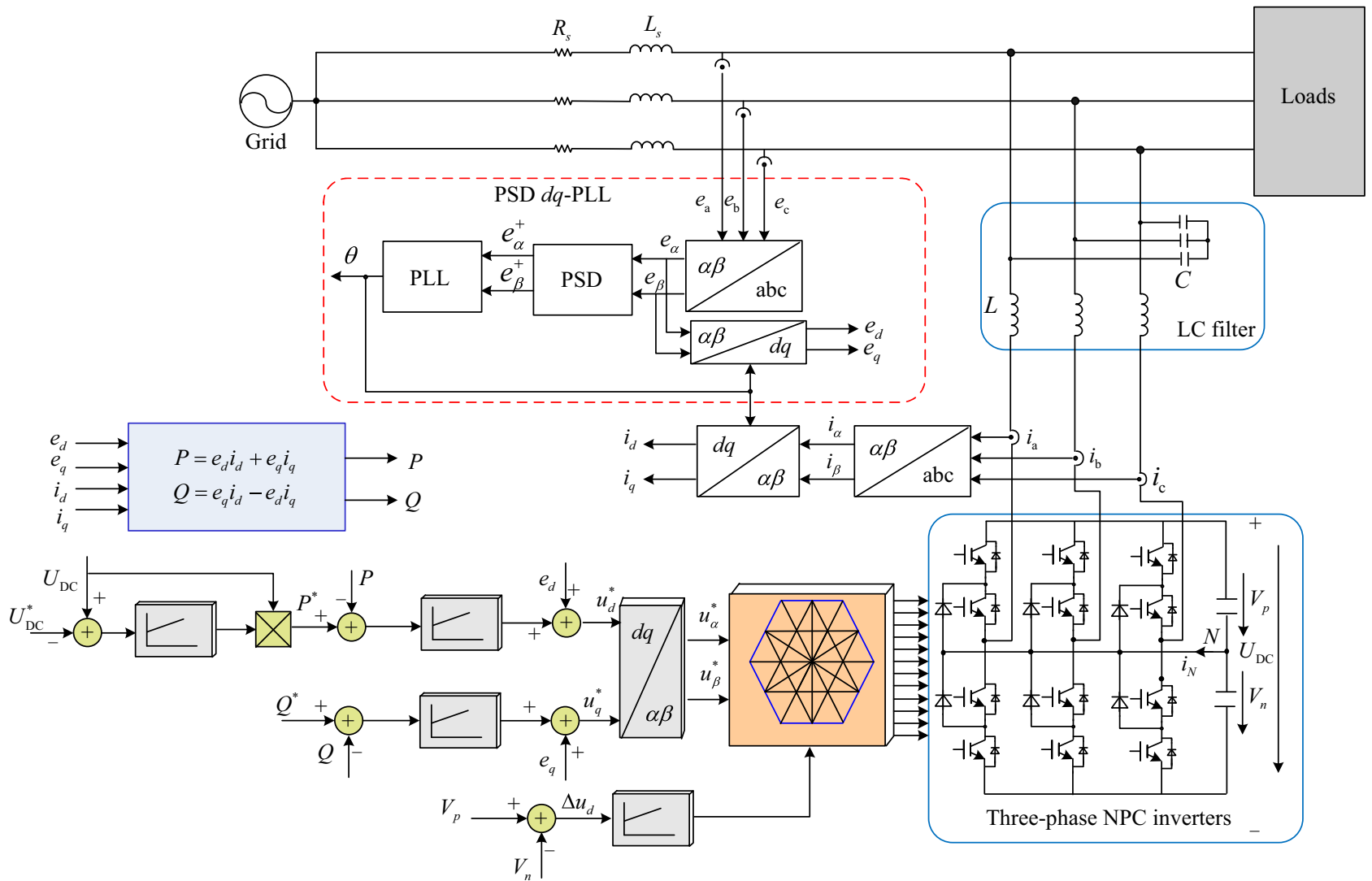

Fig. 6 DPC algorithm for three-phase three-level NPC inverters

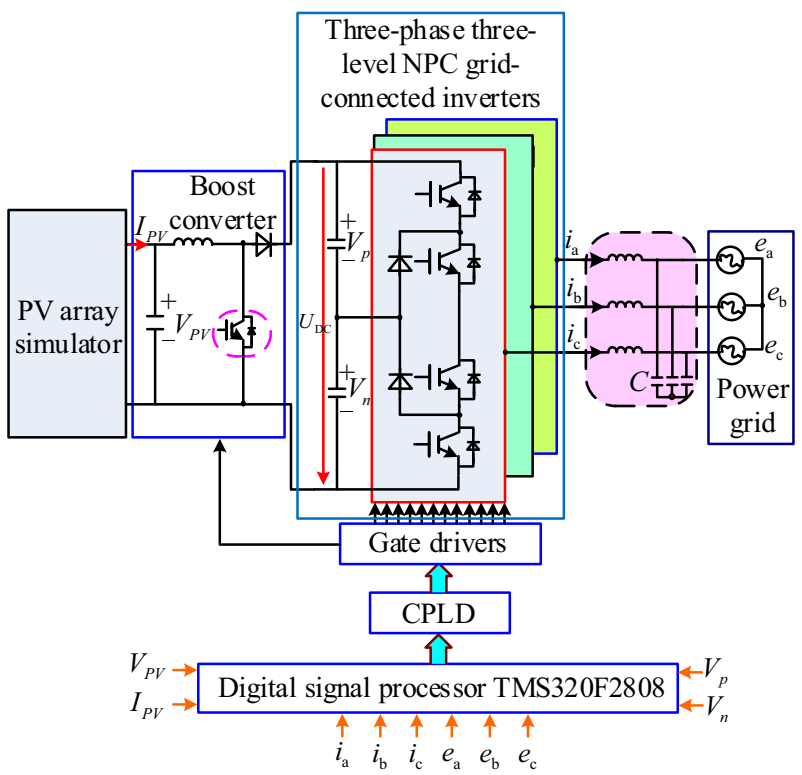

Fig. 7 Experimental block diagram for PV generation systems

proposed MPPT algorithm shown in Fig. 4 is evaluated on the established experimental bench for different conditions. In Fig. 4, a PI controller is employed when implementing the fixed P\&O MPPT method, and different perturbation values are used. In addition, the current predictive controller is used when realizing the proposed MPPT. Figure 8 shows the experimental waveforms of the fixed $\mathrm{P} \& \mathrm{O}$ MPPT method and the proposed MPPT method. Comparative experimental waveforms of phase a grid voltage $e_{\mathrm{a}}$, phase a grid current $i_{\mathrm{a}}, \mathrm{PV}$ string voltage $V_{P V}$, and $\mathrm{PV}$ string current $i_{P V}$ for different MPPT algorithms are depicted in Fig. 8 with the first PV array input. Figures 8a and $b$ show the results by using the P\&O MPPT method, and their perturbation values are $0.5 \mathrm{~V}$ and $3 \mathrm{~V}$. Figure $8 \mathrm{c}$ shows the results using the proposed MPPT scheme. Figure 8 shows that the oscillation amplitudes in the PV array voltage and PV array current are small for the three different methods. Specifically, when the inverter operates at MPP using different algorithms, the variation of the PV output voltage is measured at less than $5 \mathrm{~V}$ and the corresponding oscillation of the PV output power is measured at less than $4 \mathrm{~W}$. Thus, the static performance using these three methods are almost the same.

\section{2) Transient performance of MPPT}

The dynamic behavior of MPPT schemes has been examined under different conditions:

Case 1: Suddenly stepping input PV array from the first curve to the third curve. 
Table 1 Main parameters of PV generation system

\begin{tabular}{lll}
\hline Symbol & Parameters & Value \\
\hline$P$ & Rated power & $12 \mathrm{~kW}$ \\
$f_{s}$ & Sampling frequency & $20 \mathrm{kHz}$ \\
$V_{P V}$ & PV array input voltage & $300-900 \mathrm{~V}$ \\
$L_{1}$ & Boost converter input inductance & $1.2 \mathrm{mH}$ \\
$C_{1}$ & Boost converter input capacitor & $50 \mu \mathrm{F}$ \\
$C_{2}$ & DC-link bus voltage capacitor & $800 \mu \mathrm{F}$ \\
$e_{g}$ & Normal power grid phase voltage (RMS) & $230 \mathrm{~V}$ \\
$f_{g}$ & Normal power grid frequency & $50 \mathrm{~Hz}$ \\
$L$ & Grid filter inductance & $0.8 \mathrm{mH}$ \\
$C$ & Grid filter capacitor & $2 \mu \mathrm{F}$ \\
$k_{p V B}, k_{i V B}$ & Proportional and integral gains of boost converter voltage controller & $3.9,391$ \\
$k_{p V I}, k_{i V I}$ & Proportional and integral coefficients of inverter voltage controller & $1.5,49$ \\
$k_{p P I}, k_{i P I}$ & Proportional and integral coefficients of inverter power controller & $0.09,16$ \\
$k_{p N P I}, k_{i N P I}$ & Proportional and integral gains of inverter balancing NP voltage controller & $1.9,20$ \\
$M$ & MPPT coefficient & 0.2 \\
\hline
\end{tabular}

The proposed MPPT method is compared with the conventional fixed P\&O MPPT scheme, which has two different fixed perturbation values, $0.5 \mathrm{~V}$ and $3.0 \mathrm{~V}$ for transients. To simulate sudden irradiation changing conditions, the DC power source can be set by loading different PV array curves. Figure 9 depicts phase a grid voltage $e_{\mathrm{a}}$, phase a grid current $i_{\mathrm{a}}$, PV string input voltage $V_{P V}$, and PV string input current $I_{P V}$ for different MPPT schemes under the Case 1 condition. From Fig. 9, it can be seen that $11 \mathrm{~s}$ are needed to reach steady-state using $0.5 \mathrm{~V}$ fixed perturbation value, $9.92 \mathrm{~s}$ for $3 \mathrm{~V}$ fixed perturbation value, and only $7.60 \mathrm{~s}$ for the proposed MPPT scheme, which indicates that the proposed MPPT scheme has a faster tracking speed because of a variable and adaptive step. In Fig. 9, the PV array voltage reaches steady-state without fluctuations for the proposed MPPT scheme, while the PV array voltage uses the P\&O method with fixed perturbation value oscillations for a long period before reaching the steady-state MPP. The larger the fixed perturbation value adopted, the greater the PV array voltage oscillations before reaching the steady-state MPP. As observed from Fig. 9 in the dynamic response, it can be concluded that the proposed MPPT scheme has better transient response than the fixed perturbation value method. This will improve MPPT efficiency especially for dynamic tracking.

\subsection{Three-phase NPC inverters results}

To validate the feasibility of the DPC control strategy for the NPC inverter, the dynamic behavior is studied.
Experimental dynamic study of NPC inverters has been carried out under different conditions:

Case 2: Suddenly stepping the input PV string from the first curve to the second curve.

Case 3: Suddenly stepping the input PV string from the second curve to the first curve.

Aiming to realize the unity power factor for the NPC inverter, the reactive power reference $Q^{*}$ is set to zero. Figure 10 shows experimental waveforms of the phase a grid voltage $e_{\mathrm{a}}$, the phase a grid current $i_{\mathrm{a}}$, the phase $\mathrm{b}$ grid current $i_{\mathrm{b}}$ and the NP oscillation voltage $\Delta u_{d}$ in the different cases. Figure 10a and b display the dynamic performance under Case 2 and Case 3, respectively. As observed in Fig. 10, phase a grid current $i_{\mathrm{a}}$ is perfecly sinusoidal, and the total harmonic distortion (THD) of phase a grid current $i_{\mathrm{a}}$ is only $3.8 \%$, which is measured by a power analyzer under the second PV array. The THD of phase a grid current $i_{\mathrm{a}}$ is less than $5 \%$, which meets the national grid standard when distributed generation systems are connected to a power grid through power electronic converters.

From Fig. 10, it is seen that the NP oscillation voltage $\Delta u_{d}$ is less than $15 \mathrm{~V}$ (only $2.4 \%$ of rated voltage) in the steady-state operation and less than $30 \mathrm{~V}$ (only $5.0 \%$ of rated voltage) in the dynamic operation. This validates the effectiveness of the NP balancing control for the threelevel NPC inverter. As shown in Fig. 10, it is also concluded that the phase a grid current is in line with the phase a grid voltage in the steady-state test and even in the dynamic test and the power factor is 0.994 measured by a power analyzer under the second PV array. This means that the active power and the reactive power are successfully 


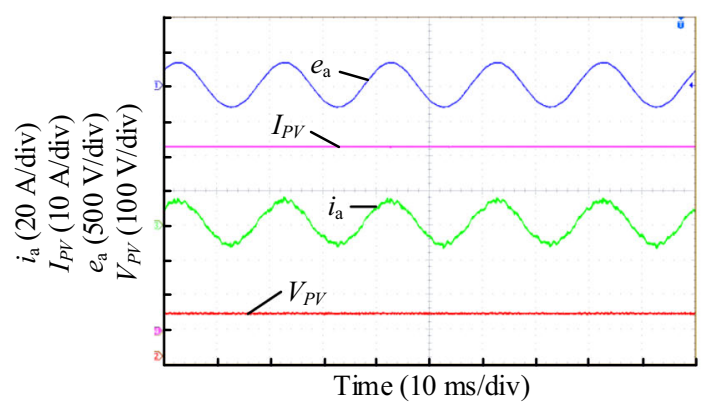

(a) $\mathrm{P} \& \mathrm{O}$ with $0.5 \mathrm{~V}$ fixed perturbation value

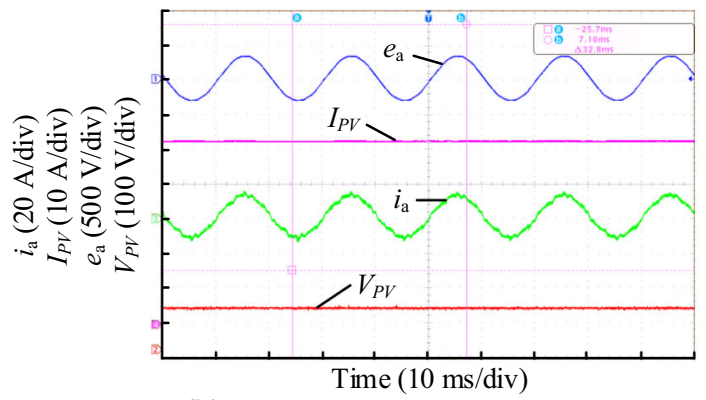

(b) $\mathrm{P} \& \mathrm{O}$ with $3 \mathrm{~V}$ fixed perturbation value

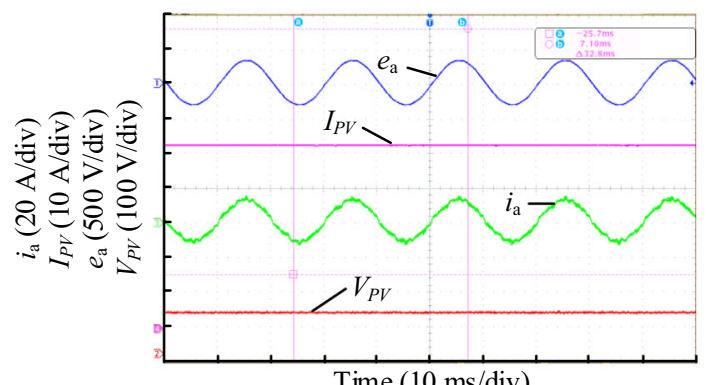

(c) Proposed MPPT method

Fig. 8 Steady-state experimental results using different MPPT methods

decoupled using DPC control with SVM. From the dynamic response in Fig. 10, it is found that the phase a grid current of the NPC inverter can reach steady-state in less than $3 \mathrm{~ms}$ under a step change, which is $50 \%$ of the rated power change, and rarely occurs in practical photovoltaic generation systems. These experimental waveforms indicate that the proposed control strategy achieves excellent steady-state and dynamic response for the threephase NPC inverter.

\section{Conclusion}

This paper presents an adaptive $\mathrm{P} \& \mathrm{O}$ and current predictive MPPT algorithm with decoupled power control applied in three-phase NPC grid-connected inverters. The conventional fixed perturbation MPPT method and

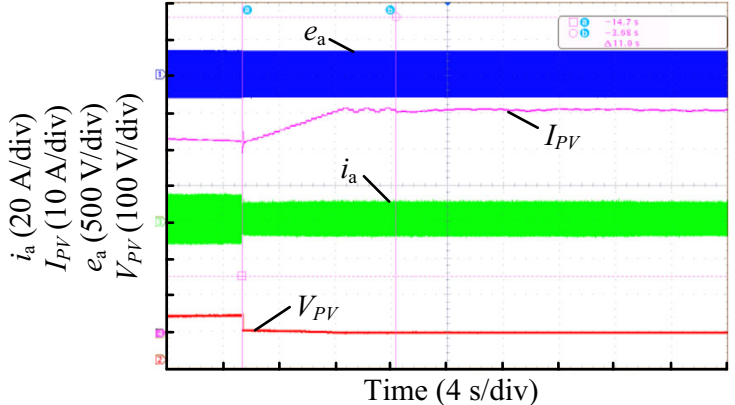

(a) $\mathrm{P} \& \mathrm{O}$ with $0.5 \mathrm{~V}$ fixed perturbation value under Case 1

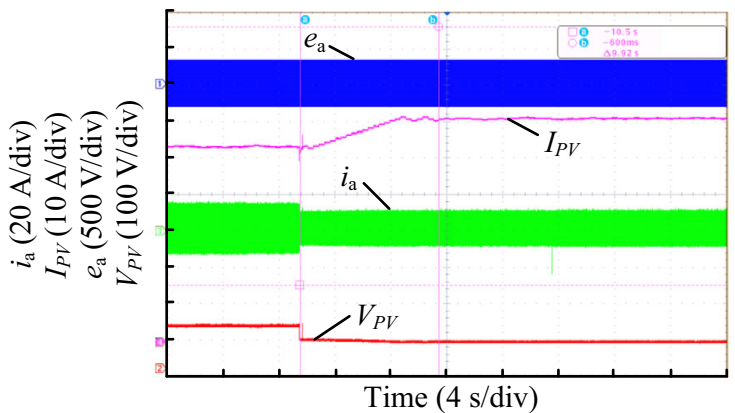

(b) $\mathrm{P} \& \mathrm{O}$ with $3 \mathrm{~V}$ fixed perturbation value under Case 1

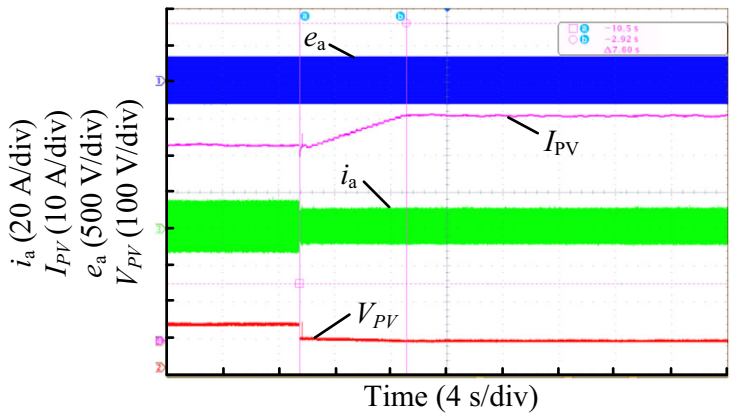

(c) Proposed MPPT method under Case 1

Fig. 9 Transient experimental waveforms using different MPPT methods

proposed method are compared in both steady-state operation and dynamic response. The results show that the proposed MPPT scheme has good steady-state and dynamic performance. The variation of the PV output voltage of the proposed MPPC method is less than $5 \mathrm{~V}$ and the proposed MPPT has faster dynamic MPPT performance than traditional methods. The proposed method only needs $7.6 \mathrm{~s}$ after getting the MMP in the dynamic process. The two other, traditional, methods require $9.92 \mathrm{~s}$ and $11 \mathrm{~s}$. In addition, decoupled control for active power and reactive power is also achieved with good steady-state and dynamic performance. The NP balancing scheme with the PI controller is very effective in balancing the NP voltage, and the NP oscillation voltage is less than $15 \mathrm{~V}$ in steady-state operation and less than $30 \mathrm{~V}$ in dynamic operation. However, the proposed current predictive MPPT control does 


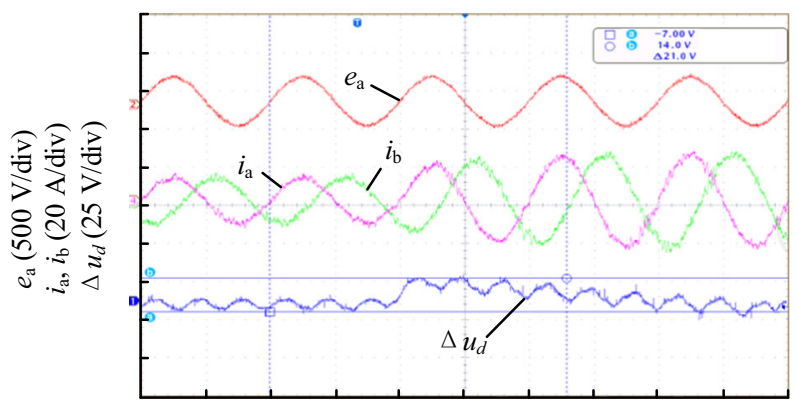

Time (10 ms/div)

(a) Under Case 2

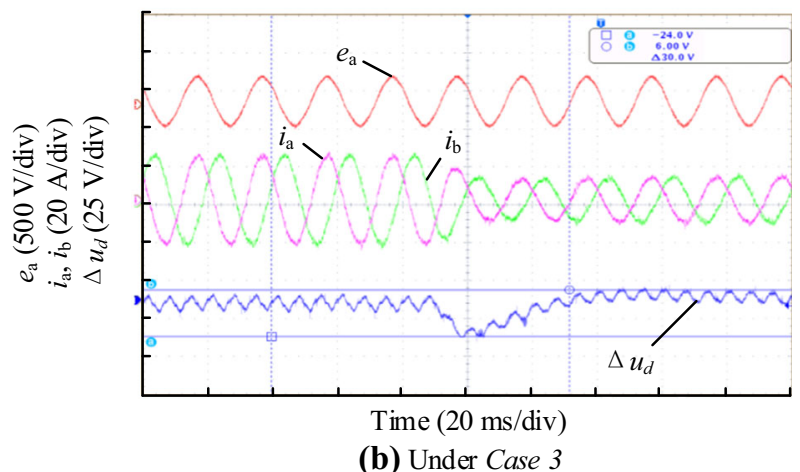

Fig. 10 Experimental waveforms of three-phase NPC inverters

not consider inductance change in the boost inverter, and the deviation value in the current predictive model will influence MPPT accuracy. Therefore, current predictive MPPT control under inductance change will be studied further in future.

Acknowledgements This work was supported in part by the National Young Natural Science Foundation of China (No. 51407124), in part by China Postdoctoral Science Foundation (No. 2015M581857), and in part by Suzhou prospective applied research project (No. SYG201640).

Open Access This article is distributed under the terms of the Creative Commons Attribution 4.0 International License (http:// creativecommons.org/licenses/by/4.0/), which permits unrestricted use, distribution, and reproduction in any medium, provided you give appropriate credit to the original author(s) and the source, provide a link to the Creative Commons license, and indicate if changes were made.

\section{References}

[1] Blaabjerg F, Ma K (2013) Future of power electronics for wind turbine system. IEEE J Emerg Sel Topics Power Electron 1(3):139-152

[2] Romero-Cadaval E, Spagnuolo G, Franquelo LG et al (2013) Grid-connected photovoltaic generation plants. IEEE Ind Electron Mag 7(3):6-20
[3] Calderaro V, Galdi V, Lamberti F et al (2015) A smart strategy for voltage control ancillary service in distribution networks. IEEE Trans Power Syst 30(1):494-502

[4] Guo X, Zhou J, Jia X et al (2018) Leakage current attenuation of a three-phase cascaded inverter for transformerless grid-connected PV systems. IEEE Trans Ind Electron 65(1):676-686

[5] Guo X, Liu W, Lu Z (2017) Flexible power regulation and current-limited control of grid-connected inverter under unbalanced grid voltage fault. IEEE Trans Ind Electron 64(9):7425-7432

[6] Hong Y, Pham SN, Yoo T et al (2015) Efficient maximum power point tracking for a distributed PV system under rapidly changing environmental conditions. IEEE Trans Power Electron 30(8):4209-4218

[7] Kollimalla SK, Mishra MK (2014) Variable perturbation size adaptive P\&O MPPT algorithm for sudden changes in radiance. IEEE Trans Sustain Energy 5(3):718-728

[8] Sundareswaran K, Vigneshkumar V, Sankar P (2016) Development of an improved P\&O algorithm assisted through a colony of foraging ants for MPPT in PV system. IEEE Trans Ind Inform 12(1): 187-200

[9] Liu F, Duan S, Liu B et al (2008) A variable step size INC MPPT method for PV systems. IEEE Trans Ind Electron 55(7):2610-2621

[10] Xu ZR, Yang P, Zhou DB et al (2015) An improved variable step size MPPT algorithm based on INC. J Power Electron 15(2):487-496

[11] Safari A, Mekhilef S (2011) Simulation and hardware implementation of incremental conductance MPPT with direct control method using Cuk converter. IEEE Trans Ind Electron 58(4):1154-1161

[12] Abdelsalam AK, Massoud AM, Ahmed S et al (2011) Highperformance adaptive perturb and observe MPPT technique for photovoltaic-based microgrids. IEEE Trans Power Electron 26(4):1010-1021

[13] Alajmi BN, Ahmed KH, Finney SJ et al (2011) Fuzzy-logiccontrol approach of a modified hill-climbing method for maximum power point in microgrid standalone photovoltaic system. IEEE Trans Power Electron 26(4):1022-1030

[14] Wei W, Zhang Z, Qiao W et al (2016) An adaptive networkbased reinforcement learning method for MPPT control of PMSG wind energy conversion systems. IEEE Trans Power Electron 31(11):7837-7848

[15] Elobaid LM, Abdelsalam AK, Zakzouk EE et al (2015) Artificial neural network-based photovoltaic maximum power point tracking techniques: a survey. IET Renew Power Gener 9(8):1043-1063

[16] Cortes P, Kazmierkowski M, Kennel R et al (2008) Predictive control in power electronics and drives. IEEE Trans Ind Electron 55(12):4312-4324

[17] Yang Y, Wen HQ, Fan MD et al (2018) A fast finite-switchingstate model predictive control method without weighting factors for T-type three-level three-phase inverters. IEEE Trans Ind Inform. https://doi.org/10.1109/TII.2018.2815035

[18] Shadmand MB, Balog RS, Abu-Rub H (2014) Model predictive control of PV sources in a smart DC distribution system: maximum power point tracking and droop control. IEEE Trans Energy Convers 29(4):913-921

[19] Errouissi R, Al-Durra A, Muyeen SM (2016) A robust continuous-time MPC of a DC-DC boost converter interfaced with a grid-connected photovoltaic system. IEEE $\mathrm{J}$ Photovolt 6(6):1619-1629

[20] Kakosimos PE, Kladas AG, Muyeen SM (2011) Implementation of photovoltaic array MPPT through fixed step predictive control technique. Renew Energy 36(2):2508-2514 
[21] Song ZF, Tian YJ, Chen W et al (2016) Predictive duty cycle control of three-phase active-front-end rectifiers. IEEE Trans Power Electron 31(1):698-710

[22] Sajadian S, Ahmadi S (2016) Model predictive-based maximum power point tracking for grid-tied photovoltaic applications using a Z-source inverter. IEEE Trans Power Electron 31(11):7611-7620

[23] Kakosimos PE, Kladas AG, Manias SN (2013) Fast photovoltaic-system voltage- or current-oriented MPPT employing a predictive digital current-controlled converter. IEEE Trans Ind Electron 60(12):5673-5685

[24] Mohamed YARI, El-Saadany EF (2007) An improved deadbeat current control scheme with a novel adaptive self-tuning load model for a three-phase PWM voltage-source inverter. IEEE Trans Ind Electron 54(2):747-759

[25] Kouro YC, Malinowski M, Gopakumar K et al (2010) Recent advances and industrial applications of multilevel converters. IEEE Trans Ind Electron 57(8):2553-2580

[26] Liserre M, Cardenas R, Molinas M et al (2011) Overview of multi-MW wind turbines and wind parks. IEEE Trans Ind Electron 58(4):1081-1095

[27] June-Seok L, Kyo-Beum L (2014) New modulation techniques for a leakage current reduction and a neutral-point voltage balance in transformerless photovoltaic systems using a threelevel inverter. IEEE Trans Power Electron 29(4):1720-1732

[28] Choi UM, Lee HH, Lee KB (2013) Simple neutral-point voltage control for three-level inverters using a discontinuous pulse width modulation. IEEE Trans Energy Convers 28(2):434-443

[29] Kazmierkowski MP, Jasinski M, Wrona G (2011) DSP-based control of grid-connected power converters operating under grid distortions. IEEE Trans Ind Inform 7(2):204-211

[30] Zhi D, Xu L, Wiliams B (2009) Improved direct power control of grid connected DC/AC converters. IEEE Trans Power Electron 24(5):1280-1292

[31] Zhang YC, Qu CH (2015) Table-based direct power control for three-phase AC/DC converters under unbalanced grid voltages. IEEE Trans Power Electron 30(12):7090-7099

[32] Zhang YC, Long YT, Zhang YC et al (2013) Table-based direct power control for three-level neutral point-clamped pulse-width modulated rectifier. IET Power Electron 6(8):1555-1562

[33] Mishra MK, Joshi A, Ghosh A et al (2003) Control schemes for equalization of capacitor voltages in neutral clamped shunt compensator. IEEE Trans Power Deliv 18(2):538-544

[34] Chaturvedi P, Jain S, Agarwal P (2014) Carrier-based neutral point potential regulator with reduced switching losses for threelevel diode-clamped inverter. IEEE Trans Ind Electron 61(2):613-624
[35] Choi UM, Blaabjerg F, Lee KB (2015) Method to minimize the low frequency neutral-point voltage oscillations with time-offset injection for neutral-point-clamped inverters. IEEE Trans Ind Appl 51(2):1678-1691

[36] Choudhury A, Pillay P, Williamson SS (2016) Modified dc-bus voltage balancing algorithm based three-level neutral point clamped IPMSM drive for electric vehicle applications. IEEE Trans Ind Electron 63(2):761-772

[37] Karimi-Ghartemani M, Iravani MR (2004) A method for synchronization of power electronic converters in polluted and variable-frequency environments. IEEE Trans Power Syst 19(3):1263-1270

Yong YANG received a B.Sc. degree in Automation from Xiangtan University, Xiangtan, China, in 2003, and an M.Sc. degree in power electronics from Guizhou University, Guiyang, China, in 2006 and a $\mathrm{Ph} . \mathrm{D}$. degree in power electronics from Shanghai University, Shanghai, China, in 2010. From 2015 to 2017, he was a postdoctoral fellow at Jiangsu GoodWe Power Supply Technology Co., Ltd., SuZhou, China. From December 2017 to December 2018, he is working as a Visiting Scholar with Center for High Performance Power Electronics (CHPPE) of The Ohio State University, Columbus, USA. He is currently a lecturer at the School of Rail Transportation, Soochow University. He has authored or coauthored more than 40 technical papers. He is the inventor or co-inventor of 17 China issued patents and several patent technologies have been applied in industry. His current research interests include model predictive control in power electronic converters, distributed energy resource interfacing and high-performance motor drive control.

Huiqing WEN received his B.S. and M.S. degrees in Electrical Engineering from Zhejiang University, Hangzhou, China, in 2002 and 2006, respectively. In 2009, he received his Ph.D. in Electrical Engineering from the Chinese Academy of Sciences, Beijing, China. From 2009 to 2010, he was an electrical engineer working with the GE (China) Research and Development Center Co., Ltd., Shanghai, China. From 2010 to 2011, he was an engineer at the China Coal Research Institute, Beijing, China. From 2011 to 2012, he was a postdoctoral fellow at the Masdar Institute of Science and Technology, Abu Dhabi, United Arab Emirates. Currently, he is an associate professor at the Xi'an Jiaotong-Liverpool University, Suzhou, China. His research interests include bidirectional DC-DC converter, power electronics in flexible $\mathrm{AC}$ transmission applications, electrical vehicles, and high-power, three-level electrical driving systems. 